\title{
Desenvolvimento, sofisticação produtiva, valor-trabalho e salários
}

Development, productive sophistication, labour-value and wages

Luiz Carlos Bresser-Pereira (1)

(1) Fundação Getúlio Vargas

\section{Abstract}

This paper, first, discusses the historical (not the normative) concept of economic development or growth, distinguish it from human development, reassert its identification with industrialization or structural change or productive sophistication. Second, it argues that the increase of wages in an integral part of the concept of growth, and offers three explanations for this: a) wages are part of effective demand, $b$ ) wages may increase with productivity, while the rate of profit tends to be constant in the long-term, and c) in the growth process, the labor-value of labor increases as the social cost of reproduction of labor increases, productive sophistication or the cost of educating and training workers and technobureaucrats increases. Third, it argues that in developing countries the increase of the productivity of labor due to the transference of labor from low valued added per capita to high value added is more important than its increase in the same industry. Finally, it argues that the relations between growth and distribution as well as between growth a protection of the environment are more positive than negative.

\section{Keywords}

growth; structural change; productive sophistication; wages.

JEL Codes O01.

\section{Resumo}

Este trabalho discute o conceito histórico (não o normativo) do desenvolvimento economico, distingue-o de desenvolvimento humano, reafirma sua identificação com industrialização ou mudança estrutural ou sofisticação produtiva; argumenta que o aumento dos salários faz parte integrante do conceito de crescimento e oferece três explicações para isso: a) os salários são parte da demanda efetiva, b) os salários podem aumentar com a produtividade, enquanto a taxa de lucro tende a ser constante no longo prazo, c) e no processo de crescimento, o valor-trabalho do trabalho aumenta porque o custo social da reprodução do trabalho se eleva à medida que aumentam a sofisticação produtiva e a necessidade de educação e treinamento dos trabalhadores e dos tecnoburocratas; afirma que o aumento da produtividade do trabalho devido à transferencia de mão de obra de setor de baixo valor adicionado per capita para de alto valor adicionado é mais importante do que o seu aumento no mesmo setor. Finalmente, argumenta que as relações entre crescimento e distribuição, bem como entre crescimento e proteção do meio ambiente, são mais positivas do que negativas.

\section{Palavras-chave}

crescimento; mudança estrutural; sofisticação produtiva; salários.

Códigos JEL O01. 


\section{Introdução}

O desenvolvimento humano ou o progresso, que discuti em outro trabalho, ${ }^{1}$ ocorre à medida que um país se aproxima dos cinco objetivos políticos fundamentais que as sociedades modernas e democráticas definiram para si mesmas nos últimos três séculos: a segurança, a liberdade, o bem-estar econômico, a justiça social, e a proteção do ambiente. $O$ desenvolvimento econômico é o componente básico desse processo mais amplo de desenvolvimento: é o processo de acumulação de capital com incorporação de progresso técnico que resulta em transformações estruturais da economia e da sociedade e no aumento dos salários e dos padrões de consumo de um Estado-Nação. É um processo histórico que ocorre a partir da revolução capitalista e, particularmente, da Revolução Industrial; é o aumento continuado da produtividade, que implica uma sofisticação cada vez maior da mão de obra empregada na produção. Incluo o aumento dos salários (ou dos salários e ordenados se distinguirmos a remuneração dos trabalhadores daquela dos tecnoburocratas ou profissionais) no conceito de desenvolvimento econômico não apenas porque o desenvolvimento econômico só faz sentido quando aumenta o padrão de consumo e a qualidade de vida das pessoas, mas também porque é isto que a história do desenvolvimento capitalista tem mostrado.

O desenvolvimento econômico é um processo histórico que, tomando-se como referência os países que primeiro se desenvolveram, nasce com a revolução capitalista, com a formação do Estado-Nação e a revolução industrial em cada país. É um processo histórico que começa com a emergência em cada país do capitalismo mercantil, em seguida com a formação do Estado-Nação e, finalmente, com a Revolução Industrial. Apenas a partir daí é possível se falar em acumulação de capital com incorporação de progresso técnico ou em desenvolvimento econômico. No plano econômico e social implica sofisticação produtiva; no plano político-institucional, a emergência da classe burguesa, o surgimento da nação como intermediária entre a sociedade como um todo e o Estado, e a construção de coalizões de classes desenvolvimentistas; no plano cultural e ideológico, finalmente, o desenvolvimento econômico implica que as duas grandes instituições das sociedades pré-capitalistas - a tradição e a religião - percam poder relativo 
para as duas instituições específicas das sociedades modernas - o Estado moderno e o mercado, e para as duas respectivas ideologias: o nacionalismo econômico (ou desenvolvimentismo) e o liberalismo econômico.

O desenvolvimento econômico passou a ser objeto de estudo especifico a partir do surgimento da development economics - a teoria dos pioneiros do desenvolvimento como Rosenstein-Rodan, Ragnar Nurkse, Arthur Lewis, Hans Singer, Raúl Prebisch, Albert Hirschman e Celso Furtado -, que hoje prefiro chamar de desenvolvimentismo clássico. Esta teoria rejeitou o pensamento neoclássico, apoiou-se no pensamento histórico dos economistas clássicos e, em menor grau, no pensamento igualmente histórico de Keynes e Kalecki. Era uma teoria desenvolvimentista na medida em que implicava o nacionalismo econômico e uma moderada intervenção do Estado na economia, e por isso a chamo de desenvolvimentismo clássico. Ela entrou em crise quando, no final dos anos de 1970, os anos dourados do capitalismo deram lugar ao capitalismo financeiro-rentista, o pensamento econômico dos governos dos países ricos e do Banco Mundial deixou de ser desenvolvimentista e keynesiano para ser liberal e neoclássico. Desde o início do século XXI, porém, observa-se a renovação do pensamento desenvolvimentista e a configuração de um pensamento novo-desenvolvimentista, do qual este estudo é uma expressão. Nele, depois de fazer uma série de considerações sobre o conceito histórico do desenvolvimento econômico, concentrarei minha atenção nos salários, que conforme argumentarei, fazem parte integrante desse conceito.

\section{Revolução capitalista, coalizão desenvolvimentista e desenvolvimento econômico}

Conforme mostrou Celso Furtado (1961, cap. 3), o desenvolvimento econômico só surge quando a apropriação do excedente é realizada principalmente no mercado, em vez de ser realizada através do poder do Estado, e quando esse excedente deixa de ser aplicado no consumo suntuário da oligarquia, na construção de palácios e templos, e no sustento de uma força armada, para ser investido em estoques e meios de transporte, e no capitalismo industrial, no investimento em máquinas e equipamentos produtivos. Assim, a partir do mercantilismo começam a surgir as condições para o desenvolvimento econômico, que ganhará plena consistência com a 
formação do Estado-Nação e a Revolução Industrial, ou seja, com a revolução capitalista. A partir de então, o desenvolvimento econômico tende a ser relativamente automático ou autossustentado, portanto, dificilmente regride, porque, em uma economia tecnologicamente dinâmica e competitiva, a acumulação de capital e o progresso técnico passam a ser uma condição de sobrevivência das empresas.

Entretanto, as taxas de crescimento econômico são tão díspares que a sorte econômica dos Estados-Nação está longe de estar assegurada depois que o país realiza sua revolução industrial. $O$ desenvolvimento econômico está sempre sujeito a crises e a eventuais paralisações de longo prazo, como vimos acontecer com a Argentina, desde a segunda metade do século XX, e no Brasil, desde 1980. Em alguns momentos o crescimento se acelera, em outros perde força, como foi o caso dos países da América Latina desde que, em torno de 1990, abandonaram o regime de política econômica desenvolvimentista e passaram a adotar o regime neoliberal ou simplesmente liberal, que deixou de ter a industrialização como seu principal objetivo, e a política cambial como um instrumento essencial para a continuidade do catching up ou alcançamento.

Quando uma economia está em pleno processo de crescimento é sinal de que estão disponíveis as instituições necessárias, as quais não são exógenas, nem se limitam à garantia da propriedade e dos contratos, como supõe o novo institucionalismo liberal; é sinal de que o país logrou definir uma estratégia nacional de desenvolvimento; que seu governo, seus empresários, técnicos e trabalhadores chegaram a um acordo básico que proporciona oportunidades de investimento lucrativo para as empresas e melhoria dos padrões de vida. Quando uma economia começa a crescer muito lentamente, ou mesmo a estagnar, é sinal de que sua solidariedade interna está em crise, que a nação perdeu coesão e se esgarçou, que já não conta, portanto, com os elementos necessários para que se mantenha competitiva.

A revolução capitalista deu origem a três novas classes sociais: em um primeiro momento, aquele que Marx conheceu, à burguesia e aos trabalhadores assalariados, e depois, já no século XX, à classe média profissional ou tecnoburocrática. Entre elas, a burguesia ou classe capitalista assume naturalmente o papel de classe dirigente, e as duas ideologias que dela vão nascer são ao mesmo tempo complementares e contraditórias: o nacionalismo, ou a ideologia da formação do Estado-Nação, e o liberalismo, a ideologia das liberdades de comerciar e de não ser molestado em sua 
autonomia individual. Essas três classes estão engajadas permanentemente dentro de cada Estado-Nação num processo dialético de conflito e cooperação: o conflito se dá pela distribuição interna do excedente, enquanto a cooperação se torna necessária para o Estado-Nação alcançar êxito na competição internacional. Como acontece sempre que a competição é recorrente envolvendo os mesmos adversários, ela implica certo grau de cooperação. Embora divididos entre direita e esquerda, entre capitalistas e socialistas, a cooperação entre os cidadãos visando constituir uma coalizão de classes desenvolvimentista é essencial para que possam atingir os objetivos políticos comuns de segurança, desenvolvimento econômico, liberdade, justiça social e proteção do meio ambiente porque é a solidariedade que define uma nação. Da mesma forma, embora divididos em Estados-Nação competitivos, os povos devem cooperar pelo menos para estabelecer as bases institucionais dessa competição.

\section{Quatro tipos de desenvolvimento econômico}

A relação entre os países que se industrializaram originalmente, o Ocidente, e os países atrasados foi sempre uma relação império-colônia ou centro-periferia, os países da periferia podendo ser simples colônias, semicolônias abertas à ocupação de seus mercados internos pelo Ocidente, ou países nacionalistas ou desenvolvimentistas. A partir do final da Segunda Guerra Mundial, a ideia de colonizar formalmente outros povos foi afinal abandonada por haver-se tornado economicamente inviável devido à reação dos povos colonizados. Por um breve período esses países, liderados pelos Estados Unidos, foram relativamente generosos em relação aos países em desenvolvimento. Entretanto, desde o surgimento dos NICs (newly industrializing countries), nos anos de 1970, que exportavam manufaturados para os países ricos usando sua mão de obra barata, a competição dos países desenvolvimentistas passou a ser vista como uma ameaça. Como resposta a essa ameaça, buscaram neutralizar a capacidade competitiva dos países em desenvolvimento através da defesa do liberalismo econômico, que, desde o início dos anos d e 1980 se tornou dominante entre eles. O principal instrumento de dominação ideológica, depois que o uso da lei das vantagens comparativas perdeu poder persuasivo, tem sido a proposta de crescimento com poupança externa, ou seja, com endividamento exter- 
no, financiado por empréstimos e pelos investimentos diretos das empresas multinacionais.

Após a Segunda Guerra Mundial, vários países lograram realizar sua revolução capitalista e industrial. Ficamos assim com dois tipos de países: os países pré-industriais e os países industriais ou sofisticados do ponto de vista tecnológico. Os países pré-industriais ainda não se industrializaram, não se sofisticaram produtivamente, portanto, não experimentaram o desenvolvimento econômico em sentido estrito, não contam ainda com um setor industrial significativo, um mercado competitivo, e o processo de acumulação com incorporação de progresso técnico não se tornou uma condição de sobrevivência das empresas. Os países industriais são aqueles que já realizaram sua revolução capitalista, portanto, já experimentaram o desenvolvimento econômico, e podemos ver quatro tipos de desenvolvimento econômico que trilharam ou estão trilhando, conforme seu caráter for central, ou periférico - central porque referente a países europeus mais ricos, que foram os primeiros a se industrializar; periférico, se o país por algum tempo, e em diversos graus, foi dominado, formal ou informalmente, pelo imperialismo industrial ou moderno.

1) Desenvolvimento central original, dos países que primeiro se industrializaram (Inglaterra, Bélgica, França e Estados Unidos);

2) Desenvolvimento central atrasado, de países europeus como a Alemanha, a Rússia, a Áustria e a Suécia, que realizaram suas revoluções industriais na segunda metade do século XIX;

3) Desenvolvimento periférico autônomo, dos países que também foram colônias ou se submeteram ao imperialismo no século XIX, mas logo em seguida, como foi o caso do Japão, ou então a partir da Segunda Guerra Mundial, como é o caso da Coreia, da China ou da Índia, lograram um grau de autonomia política elevado;

4) Desenvolvimento periférico nacional-dependente, dos países que foram colônias, tornaram-se formalmente independentes, mas continuam a apresentar vários graus de dependência cultural em relação ao centro, como os países da América Latina.

O primeiro tipo de desenvolvimento econômico, central original, tem sido estudado por um sem-número de analistas. $O$ segundo, central atrasado, teve em Gerschenkron (1962) seu analista pioneiro. Do ponto de vista político e cultural, países que faziam parte do centro e que atrasaram em se unificar ou formar seu Estado-Nação só lograram formar um grande 
mercado interno e se industrializar quase cem anos depois da Revolução Industrial, na Inglaterra. O terceiro tipo de desenvolvimento econômico, periférico autônomo, teve como modelo o Japão, que considero também periférico, porque foi também objeto do imperialismo ocidental entre 1854 e 1868. Seus analistas maiores são Barbosa Lima (1973), Chalmers Johnson (1982), Robert P. Dore (1986), Alice Amsden (1989) e Robert Wade (1990) - estes dois últimos estudaram, respectivamente, Coreia do Sul e Taiwan, dois países que seguiram o modelo japonês.

Celso Furtado (1961) foi provavelmente o economista que melhor estudou o quarto tipo de desenvolvimento, nacional-dependente, ao definir o subdesenvolvimento não como um simples atraso, mas como a relação subordinada em relação aos países ricos, e ao ver o desenvolvimento econômico como o resultado de um projeto nacional. Ele não aceitou a teoria da dependência tanto na sua versão associada, que afinal submetia o país aos países ricos, como na sua versão superexploração imperialista, pois não acreditava que a única alternativa para os países latino-americanos era a revolução socialista. Mas não chegou a definir com clareza o que eu denomino desenvolvimento nacional-dependente ${ }^{2}$ - um processo de desenvolvimento econômico contraditório na medida em que as elites locais, especialmente nos países latino-americanos, são ambíguas e não logram completar a revolução nacional em seus respectivos países - ou seja, não logram criar um Estado-Nação com a autonomia necessária para promover seu próprio desenvolvimento econômico. De um lado, as sociedades nacional-dependentes são submetidas à permanente hegemonia ideológica dos países ricos, que não estão interessados no desenvolvimento dos países de renda média, mas na neutralização de sua capacidade competitiva internacional; de outro lado, percebem esse fato, e se comportam como elites nacionais que buscam formular estratégias nacionais de desenvolvimento. A expressão nacional-dependente é propositalmente um oximoro para indicar essa ambiguidade intrínseca - uma ambiguidade que, desde a Segunda Guerra Mundial, países como a China ou a Coreia souberam como enfrentar nos termos do seu interesse nacional.

Dessas quatro formas históricas de desenvolvimento econômico resultam, hoje, três tipos de países quanto ao nível de desenvolvimento: países ricos, que compreendem os países de desenvolvimento original Japão, 
Coreia do Sul, Taiwan e Singapura; países de renda média, como o Brasil, Argentina, México, Chile, Uruguai, Rússia, Turquia, Índia e a China, que realizaram sua revolução capitalista, mas ainda não logram integrar toda a sociedade no modo de produção capitalista; e países pré-industriais, que ainda não se industrializaram.

O quadro mundial em que hoje ocorre o desenvolvimento econômico é o da hegemonia ideológica dos países ricos - particularmente dos Estados Unidos -, através da qual esses países, que constituem o Ocidente, têm como política fundamental ocupar os mercados internos dos países de renda média com seu comércio, seus financiamentos e principalmente com suas empresas multinacionais. Os países ricos continuam a se desenvolver, mas lentamente; os países periféricos autônomos continuam a crescer aceleradamente e realizam o catching up; e os países periféricos nacional-dependentes - desde os anos de 1980 mais dependentes do que autônomos - crescem lentamente desde então e deixaram de realizar o alcançamento. Dessa maneira, considerando os países pré-industriais e os países nacional-dependentes, que constituem a grande maioria dos Estados-Nação, o catching previsto pela teoria econômica é essencialmente uma ilusão. Essa previsão está baseada em duas vantagens na competição internacional: a mão de obra barata e a possibilidade de copiar ou comprar tecnologias a um custo relativamente baixo. Entretanto, essa vantagem só se transforma em realidade se o país em desenvolvimento, que, em princípio, conta com instituições e regimes políticos mais instáveis, lograr autonomia suficiente para formular uma estratégia nacional de desenvolvimento. Os países periféricos do Leste da Ásia foram capazes de conservar sua autonomia nacional, foram bem-sucedidos em manter níveis elevados de poupança e investimento e aproveitaram essa oportunidade que a globalização comercial acentuou ao thes abrir mercados para exportar para os países ricos bens com crescente grau de sofisticação produtiva ou valor adicionado per capita. Já os países que seguem um padrão nacional-dependente ficaram para trás na grande competição global. Tanto o êxito de uns quanto o fracasso de outros estão relacionados com sua capacidade de resistir ao pensamento hegemônico vindo do Ocidente e à sua capacidade de estimular a poupança e o investimento.

A partir dessa perspectiva, vemos que o desenvolvimento econômico depende da acumulação de capital e da sofisticação produtiva, que, por sua vez, resultam em aumento da produtividade e dos salários. $\mathrm{O}$ aumento dos salários não é, porém, mera consequência do desenvolvimento econômico, 
mas parte integrante dele. Não há desenvolvimento econômico se não houver aumento dos salários reais, portanto, dos padrões de vida da população. Mais do que isso: ainda que no capitalismo possamos assistir a períodos relativamente longos de aumento das desigualdades, se os salários não aumentarem esse desenvolvimento não se sustentará. Antes, porém, de procurar substanciar o que estou afirmando, quero brevemente ver o desenvolvimento econômico como sofisticação produtiva, ou, mais concretamente, como industrialização, porque essa análise será importante para meu argumento.

\section{Desenvolvimento econômico e sofisticação produtiva}

Desenvolvimento econômico implica industrialização, mudança estrutural ou sofisticação produtiva - três expressões praticamente sinônimas. Nas situações normais, o aumento da renda per capita é acompanhado por sofisticação produtiva, mudança das instituições, e mudanças no plano cultural, de forma que aumento da renda per capita sem sofisticação produtiva torna-se um evento improvável. A causa fundamental disso está na contribuição decisiva de Marx quanto à interdependência entre as duas instâncias da sociedade: a infraestrutura e a superestrutura, esta dividida em instituições e em ideologias. A mudança interdependente dessas três instâncias (a econômica ou das formas de propriedade, a institucional ou da lei e demais instituições normativas e organizacionais, e a cultural ou das ideologias e religiões) tornou-se assente para quem quer que pense historicamente. Nenhuma dessas instâncias pode mudar sem que, mais cedo ou mais tarde, as outras também mudem. Não há consenso sobre qual dessas instâncias é a mais estratégica, nem é possível prever quando a mudança em uma instância provocará mudança na outra, mas sua interdependência é um fato social indiscutível. Nessa linha de pensamento, Carlos Aguiar de Medeiros (2001) salienta que a diferença essencial entre essa proposição e o determinismo institucional de North é que este não supõe, como Marx, a adequação das instituições e do poder político às relações de produção; para novo institucionalismo as instituições são exógenas e podem tolher, permanentemente, o desenvolvimento.

Existe uma longa tradição na literatura econômica que rejeita a identificação de desenvolvimento econômico com crescimento da renda e o entende como sofisticação produtiva. Schumpeter (1911) foi o primeiro 
economista a assinalar a distinção entre desenvolvimento e crescimento econômico ao afirmar que o desenvolvimento econômico implica transformações estruturais do sistema econômico que o simples crescimento da renda per capita não assegura. Schumpeter usou essa distinção para salientar a ausência de lucro econômico no fluxo circular onde, no máximo, ocorreria crescimento e para mostrar a importância, no verdadeiro processo de desenvolvimento econômico, da inovação, da vantagem competitiva que ela assegura, e do aumento da taxa de lucro. $O$ desenvolvimentismo clássico geralmente seguiu essa linha. Para Celso Furtado (1967, p. 74-76), a questão não era tão simples: o desenvolvimento compreende a ideia de crescimento, superando-a, mas, complementa, para que o crescimento não acarretasse modificações na estrutura econômica, seria preciso pensar em uma situação pouco provável na qual ocorresse a expansão simultânea de todos os setores produtivos sem qualquer aumento da produtividade. E conclui: o crescimento é o aumento da produção, ou seja, do fluxo de renda, ao nível de um subconjunto especializado, e o desenvolvimento é o mesmo fenômeno do ponto de vista de suas repercussões no conjunto econômico de estrutura complexa que inclui o anterior (itálico de Furtado).

Realmente, os casos em que ocorre crescimento da renda per capita sem que haja desenvolvimento econômico, sem que haja sofisticação produtiva e melhoria dos padrões de vida da população, são relativamente raros. Ocorrem em países com doença holandesa e estritamente rentistas, como a Arábia Saudita e a Nigéria, nos quais a abundância de recursos naturais, que, em princípio, seria uma bênção, se transforma em uma maldição, e o Estado, como bem observou Peter Evans (1992), é um Estado predador. Nesse quadro suas elites corruptas limitam-se ao rent-seeking e capturam integralmente as rendas associadas à abundância de recursos naturais, em vez de tratarem de neutralizar a desvantagem competitiva de que suas economias são vítimas e organizarem a produção nacional. Nesses casos, a taxa de câmbio permanece sobreapreciada no longo prazo, torna-se mais barato importar, e a industrialização torna-se inviável. Mas como a população trabalhadora local está desorganizada politicamente, ela vive no nível de sobrevivência, e apenas a elite política e econômica e os interesses estrangeiros se aproveitam da taxa de câmbio apreciada para importar bens de luxo, ou ir às metrópoles consumi-los diretamente.

Uma comprovação empírica muito interessante da relação direta entre desenvolvimento econômico e sofisticação produtiva foi oferecida pelo 
Mapa da Complexidade Econômica, de Hausmann e Hidalgo (2014). Os autores criaram o Observatório da Complexidade - uma parceria entre o MIT e a Universidade de Harvard - e montaram uma grande base de dados que mostra com clareza o grau de complexidade de cada país e sua direta relação com o desenvolvimento econômico. Para medir essa complexidade usaram dois conceitos básicos - a ubiquidade e diversidade de produtos encontrados na sua pauta exportadora, uma informação que é disponível para quase todos os países desde os anos de 1950. Se uma determinada economia é capaz de produzir bens não ubíquos, que apenas alguns países produzem, e se sua pauta de exportação é diversificada, há indicação de que conta com um tecido produtivo complexo, portanto, sofisticado e desenvolvido.

\section{Desenvolvimento econômico, salários e valor}

O aumento dos salários reais ou do padrão de consumo da população é uma característica essencial do conceito de desenvolvimento econômico. Isto é valido mesmo que o país não tenha completado sua revolução capitalista ou atingido o ponto Lewis, a partir do qual deixa de haver oferta ilimitada de mão de obra (Lewis, 1954). Mesmo no caso em que isso não aconteceu ainda, mas o desenvolvimento econômico já estiver em marcha, haverá aumento real de salários. Será, porém, substancialmente menor do que o aumento da produtividade, como aconteceu, por exemplo, no Brasil, cujos salários reais aumentaram desde que se iniciou a revolução capitalista, em torno de 1930 até os anos de 1990, quando o ponto de Lewis deve ter sido atingido e os contratos informais de trabalho começaram a diminuir. A afirmação que faço neste artigo - que no quadro do desenvolvimento capitalista os salários e o padrão de consumo passam a crescer - não é normativa, não expressa valores, mas é histórica. Em todos os episódios de desenvolvimento econômico de longa duração os salários e os padrões de vida aumentam - a uma taxa maior ou menor do que aumenta a produtividade, com diminuição ou aumento da desigualdade, mas sempre aumentam. Certamente porque os trabalhadores se organizaram, aumentaram seu poder de barganha e pressionaram, visando aumentos de salários e de condições de trabalho. Mas, além desse argumento político há três explicações estritamente econômicas para o caráter imperativo do aumento dos salários. 
A primeira é o conhecido argumento do lado da demanda, associado à teoria do subconsumo das crises econômicas. $\mathrm{O}$ aumento dos salários na proporção do aumento da produtividade possibilita o equilíbrio entre a oferta e a procura agregada. Mas isso não significa que não possa haver descompasso entre o aumento dos salários e o aumento da produtividade, como aconteceu no Brasil nos anos de 1970. Nessa década tivemos forte aumento da produtividade enquanto os salários dos trabalhadores cresciam abaixo desse aumento, mas isso só foi possível graças ao fato que os ordenados e os demais rendimentos da classe média criaram demanda por bens de consumo duráveis. Pode também haver esse descompasso durante certo tempo, se o país lograr montar um sistema em que apenas o setor de bens de produção aumenta, criando demanda endogenamente, dentro do próprio setor; mas esse caso, cujo melhor exemplo é o da União Soviética entre 1930 e 1960, só foi viável no início do processo histórico do desenvolvimento. Uma terceira possibilidade é a de que o país aumente seu coeficiente de exportações, encontrando, assim, saída para sua produção sem que os salários aumentem, mas o extraordinário crescimento da China a partir de 1980, fortemente voltado para as exportações, que poderia ser um exemplo, acabou resultando em um grande aumento de salários para os trabalhadores. Nos três casos a alternativa ao aumento dos salários é sempre temporária e tem poder limitado de conter os salários.

A segunda explicação para o que o salário cresça quando aumenta a produtividade diz respeito à natureza intrinsecamente diferente da taxa de salários e da taxa de lucro. Os salários e os padrões de vida aumentam quando há crescimento porque a taxa de lucro média de uma economia nacional certamente varia no curto prazo, mas o aumento da taxa de lucro em prejuízo da taxa de salários é algo limitado, porque, para os salários reais não há limite de crescimento desde que esteja aumentando a produtividade, enquanto que para a taxa de lucro não existe essa possibilidade devido à concorrência entre os capitais. Conforme Bresser-Pereira argumentou (1986, 2014a), a taxa de lucro tende a permanecer constante no longo prazo, enquanto os salários tendem a crescer em torno do aumento da produtividade. ${ }^{3}$ Ao fazer essa afirmação, ele inverteu a teoria clássica da distribuição de Ricardo e Marx, segundo a qual os salários são dados

3 Existe uma ampla literatura empírica que confirma essa tese da relativa constância da taxa de lucro no longo prazo e do aumento da taxa de salários com a produtividade. Ver, principalmente, Thomas Weisskopf (1979), Armstrong e Glyn (1991), Duménil e Lévy (2002). 
no nível de subsistência enquanto os lucros são o resíduo. Não foi isso que se observou historicamente. Os salários não se mantiveram no nível de subsistência, mas cresceram com a produtividade, enquanto os lucros, embora flutuando com o ciclo econômico, mantinham-se relativamente estáveis no longo prazo. A primeira e mais simples razão para isto é que, dada a ampla oferta de capitais acumulados e dada a concorrência entre as empresas, a taxa de lucro não pode crescer indefinidamente, enquanto a taxa de salários pode, como veremos na terceira explicação. $\bigcirc$ que existe no capitalismo à medida que ele vai se tornando maduro não é uma oferta ilimitada de mão de obra, mas uma oferta ilimitada de capitais. Algumas empresas gozam de uma posição monopolista muito forte, e sua taxa de lucro pode ser muito alta, mas na média das empresas a concorrência acaba prevalecendo sobre o monopólio mesmo no caso de setores oligopolistas. Para supor que a taxa de lucro permanece constante Bresser- Pereira não se vale do modelo de Goodwin (1967), segundo o qual a taxa de lucro se manteria constante através de um processo cíclico endógeno. Em vez disso, ele argumenta que a taxa de lucro se mantém constante em um nível satisfatório para as empresas (o nível que motiva as empresas a investir) porque esta é uma condição da existência do capitalismo. Ora, como não se encontrou ainda um substituto para o capitalismo, ainda que o progresso técnico seja dispendioso de capital, a taxa de lucro é mantida constante, e o custo do ajuste fica por conta dos salários, que passam a crescer menos do que a produtividade. Nos termos do modelo, a taxa de salário cresce em torno do crescimento da produtividade - crescendo menos, igual ou mais rapidamente que a produtividade, dependendo de o progresso técnico ser respectivamente dispendioso de capital, neutro, ou economizador de capital. No progresso dispendioso de capital, também chamado de mecanização, temos a queda da relação produto-capital ou da produtividade do capital porque a substituição de tipos de trabalho por tipos de capital segue uma ordem decrescente: começa-se com a substituição do trabalho por máquinas muito mais eficientes do que o trabalho substituído, e, uma vez esgotado esse tipo de substituição, se passa a substituir novos tipos de trabalho por novas máquinas relativamente menos eficientes, que implicam menor relação produto-capital. Para Marx, esse tipo de progresso técnico seria dominante e implicaria queda da taxa de lucro já que no modelo clássico a taxa de salários era dada. Na verdade, a taxa de lucro é que permanece constante, e a taxa de salário passa a crescer menos do 
que a produtividade. Poderia até cair, mas esse evento é pouco provável, e até hoje não tenho notícia de que tenha ocorrido. ${ }^{4}$ Nesses termos, no longo prazo, a partir de uma perspectiva de oferta ou do progresso técnico, quando ocorre o aumento da produtividade do trabalho, os salários reais dos trabalhadores continuarão a aumentar sem colocar em risco a taxa de lucro, mesmo que a produtividade do capital esteja caindo: os salários simplesmente aumentarão a uma taxa menor do que o aumento da produtividade do trabalho. Foi aproximadamente isso que aconteceu a partir dos anos de 1980 nos Estados Unidos. Nos anos de 1970 houve estrangulamento dos lucros, causado pelo progresso técnico dispendioso de capital e pelo aumento do poder de barganha dos trabalhadores desde o fim da Segunda Guerra Mundial. Diante disso, o capitalismo financeiro-rentista reagiu, a partir dos anos de 1980, de forma agressiva e restabeleceu a taxa de lucro, enquanto os salários em geral passaram a crescer menos do que a produtividade e os salários mais baixos estagnaram.

Proponho, porém, que existe um terceiro e poderoso argumento para que os salários reais cresçam de maneira proporcional ao desenvolvimento capitalista: o desenvolvimento econômico implica, necessariamente, o aumento do valor do trabalho, porque ele exige trabalhadores, engenheiros etc. de nível cada vez mais sofisticado do ponto de vista tecnológico, e à medida que o valor do trabalho aumenta os salários devem aumentar correspondentemente. Os economistas clássicos utilizaram a teoria do valor-trabalho para prever a estagnação secular do capitalismo. Eles previam, no longo prazo, a queda da taxa de lucro e a estagnação da economia capitalista, porque previam ou supunham um valor constante do trabalho e rendimentos decrescentes da terra (Ricardo) ou do capital (Marx). A história econômica se encarregou de demonstrar que os rendimentos decrescentes não se comprovaram - pelo contrário, hoje está cada vez mais claro que o desenvolvimento tecnológico implica rendimentos crescentes. Segundo, nos países ricos o valor do trabalho - a quantidade de trabalho abstrato necessária para a reprodução e manutenção dos trabalhadores - não se revelou constante, no nível de subsistência, mas cresceu. Marx já havia percebido esse fato no seu tempo e por isso falou que esse nível mudava historicamente, era socialmente determinado. Mas tituição de máquinas velhas por máquinas novas mais eficientes que substituem o mesmo tipo de trabalho. 
para ele o valor-trabalho continuou associado à subsistência do trabalhador. Minha proposta é que excluamos o nível de subsistência do conceito de valor-trabalho e fiquemos apenas com o conceito que ele corresponde ao custo de reprodução e manutenção da força de trabalho. Para continuarmos a associar diretamente o nível de subsistência ao custo de reprodução da força de trabalho precisamos dar um sentido tão elástico ao historicamente definido que ele passaria a não significar coisa alguma. Redefinido assim o valor-trabalho, simplesmente como custo de reprodução e manutenção da força de trabalho, e reconhecendo que ele é hoje substancialmente superior ao mero nível de subsistência, compreendemos por que as empresas podem pagar aos seus trabalhadores um salário superior ao nível de subsistência sem comprometer uma taxa de lucro satisfatória; porque a taxa de lucro pode ser constante no longo prazo; elas estão simplesmente pagando aos trabalhadores o que custa para suas famílias e a eles próprios sua educação em sentido amplo, formal e informal, e esse custo está incluído no valor e no preço das mercadorias e serviços que elas produzem e vendem. $O$ custo de reprodução ou o valor-trabalho dos diversos tipos de trabalho - o investimento em saúde e principalmente em educação nela realizado - é tanto maior quanto mais sofisticado tecnológica e administrativamente for esse trabalho. Os custos de formar trabalhadores, administradores, técnicos e assessores de todos os tipos envolvidos na produção capitalista direta e indiretamente são cada vez maiores, envolvem cada vez mais gastos com educação superior e pós-graduação, portanto, seu valor-trabalho é cada vez maior, implicando um salário, igualmente, cada vez maior.

Assim, a empresas que empregam essa mão de obra não fazem mais do que pagar na forma de salários seu custo de reprodução. Ao contrário, entretanto, do que pensavam os economistas clássicos, esse custo de reprodução não é o de subsistência, mas um custo que envolve um investimento elevado em capital humano e proporciona salários ou ordenados substancialmente maiores aos indivíduos beneficiados por esse investimento. Isso não significa, naturalmente, que o conceito de mais-valia deixa de valer. O trabalhador assalariado continua produzindo mais do que seu custo de reprodução, portanto, a mais-valia continua a ser apropriada. O que muda é que a classe capitalista e a alta tecnoburocracia não se apropriam de todo o excedente, mas de parte dele. Definido o valor da força de trabalho nesses termos, os salários giram em torno desse valor de acordo com a oferta 
e a procura de mão de obra, como acontece para qualquer bem ou serviço. E, também, de acordo com o poder de barganha dos trabalhadores.

Em síntese, enquanto a taxa de salários aumenta com o desenvolvimento econômico, a taxa de lucro tende a permanecer constante no longo prazo. Ela varia através dos ciclos, mas se mantém em um nível satisfatório que motive o empresário a investir. Ele naturalmente quer o lucro o mais alto possível, mas sabe que não pode subordinar sua necessidade de realização pessoal, de investir e inovar, de construir um império, a esse desejo de lucros extraordinários; sabe que tal condição não é realista nem no plano econômico (dada a concorrência), nem no político (dada a vigilância da sociedade). Basta-lhe, então, uma taxa de lucro satisfatória (Simon, 1957) que, por essa razão, tende a ser constante no processo de longo prazo de desenvolvimento capitalista: a taxa média de lucro de longo prazo só aumentaria ou se reduziria se, por alguma razão, o nível convencionalmente considerado satisfatório pelos empresários aumentasse ou diminuísse. Por outro lado, vimos que o valor-trabalho aumenta à medida que a sofisticação produtiva ocorre e define o desenvolvimento econômico. $\bigcirc$ aumento da remuneração dos trabalhadores e dos tecnoburocratas decorre, portanto, de um fato econômico muito concreto. A organização dos trabalhadores e a posição estratégica dos tecnoburocratas na produção desempenham um papel, mas esse papel é essencialmente o de não deixar que os salários e ordenados se desvinculem do valor do trabalho. Os dois argumentos nos levam, portanto, a prever que o aumento da produtividade e o aumento dos salários crescerão de forma aproximadamente igual desde que não haja uma mudança do tipo de progresso técnico de neutro para dispendioso de capital. No processo histórico do desenvolvimento capitalista, os salários dos trabalhadores e os ordenados da classe média profissional crescem estruturalmente em função do aumento da produtividade, considerados os tipos de progresso técnico; crescem porque os investimentos e o crescimento econômico implicam maior demanda de trabalhadores cada vez mais qualificados; crescem porque esses salários são compatíveis com uma taxa de lucro no longo prazo constante e satisfatória; crescem porque os trabalhadores lutam por melhores salários; crescem porque a lógica do equilíbrio entre a oferta e a demanda agregada o exige; e, last but not least, crescem porque o custo de reprodução da mão de obra aumenta à medida que seu conteúdo tecnológico, organizacional e comunicativo se sofistica. $\bigcirc$ aumento dos salários é, portanto, parte integrante do desenvolvimento econômico. 


\section{Desenvolvimento no próprio setor ou como transfe- rência?}

A elevação da produtividade do trabalho é sinônimo de crescimento econômico. Os dois fatores fundamentais a determiná-la são a taxa de acumulação de capital, que aumenta diretamente a produção por trabalhador, e a relação produto-capital ou produtividade do capital. Nos dois casos temos incorporação de progresso técnico na produção e aumento da produtividade do trabalho. No caso do investimento, o progresso técnico é incorporado nas máquinas; no caso da variação na produtividade do capital, essa incorporação tem um efeito ampliador, redutor, ou neutro, conforme o progresso técnico seja poupador de capital, dispendioso de capital, ou neutro. Em outras palavras, os dois processos implicam economia de trabalho: o investimento, ao permitir a substituição direta de trabalho por máquinas; o aumento da produtividade do capital, ao tornar os bens de capital mais baratos, portanto, ao reduzir o custo do capital que entra na formação do valor e do preço das mercadorias e dos serviços produzidos.

Mas há uma terceira forma de se aumentar a produtividade do trabalho. Em vez de ela ocorrer no mesmo setor, graças à acumulação de capital, à melhoria da qualidade das máquinas, à melhoria da qualidade dos trabalhadores, à melhoria dos processos produtivos, ela pode acontecer simplesmente através da transferência de mão de obra de setores com baixo valor adicionado per capita para setores com alto valor adicionado per capita. Essa transferência supõe utilização melhor e imediata do nível de educação dos trabalhadores e técnicos disponíveis. Em uma economia capitalista é comum a existência de maior capacidade produtiva humana do que emprego para ela. Ela pode ficar presa na agricultura, ou em atividades manufatureiras e de serviço de baixa complexidade. Quando ocorre a transferência de mão de obra para a indústria, ocorre aumento médio da produtividade de toda a economia nacional e aumentam os salários. Esta é, a meu ver, a principal razão pela qual estavam certos os economistas desenvolvimentistas clássicos quando afirmavam que desenvolvimento econômico é industrialização, é mudança estrutural, é - em uma linguagem mais ampla para incorporar os serviços tradable complexos - sofisticação produtiva.

Há outra maneira de associar industrialização a sofisticação produtiva. Nicholas Kaldor (1957) formalizou essa ideia por meio de sua função de progresso técnico, que estabeleceu a existência de uma relação estrutural 
entre a taxa de crescimento do produto por trabalhador e a taxa de crescimento do capital por trabalhador. Para ele é impossível distinguir entre o crescimento da produtividade que resulta da incorporação de novas tecnologias e aquele que resulta de um aumento do capital por trabalhador, pois a maioria das inovações tecnológicas que aumenta a produtividade do trabalho demanda a utilização de um maior volume de capital por trabalhador. Mas é possível afirmar que a acumulação de capital com incorporação de progresso técnico beneficia-se, com frequência, de economias de escala, ou implicam progresso técnico poupador de capital. Essa é uma possibilidade, mas, conforme observei quando discuti os três tipos de progresso técnico, o progresso técnico poupador de capital, associado à ideia de rendimentos crescentes ou a economias dinâmicas de escala, acontece quando há substituição de máquinas antigas por máquinas mais eficientes - algo que tornaria essa associação ou esse argumento mais forte no caso dos países ricos, nos quais é de se esperar que a substituição de máquinas antigas por máquinas novas realizando o mesmo trabalho tenha maior peso do que a mecanização ou o progresso técnico dispendioso de capital, definido pela substituição de novos tipos de trabalho por novas máquinas que são mais eficientes do que o trabalho substituído, porém, menos eficientes do que as máquinas anteriores que substituíram tipos de trabalho anteriores. Nesses países, que estão na fronteira do desenvolvimento tecnológico, o argumento de Kaldor relativo aos rendimentos tem maior validade do que nos países em desenvolvimento para os quais o argumento da transferência de mão de obra é fundamental. Por isso, entendo ser um equívoco dar ao argumento relativo a economias de escala importância maior do que o argumento da mudança estrutural através da transferência de mão de obra para os setores mais sofisticados tecnológica e administrativamente, que devemos a Prebisch (1949), Nurkse (1953) e Furtado (1958). Correlatamente, tornou-se frequente na literatura sobre o desenvolvimento econômico a relação causal entre a taxa de crescimento do PIB e a taxa de crescimento da produtividade. Essa relação é conhecida como Lei de Kaldor-Verdoorn (León-Ledesma 2002). Nesse cenário, inverte-se a relação entre aumento da produtividade e crescimento da produção, o aumento do PIB levando ao aumento da produtividade. Não tenho objeção a essa tese porque o aumento da demanda agregada é essencial para que as empresas invistam; porque não há crescimento sem investimento, e não há investimento sem que haja demanda que crie oportunidades de investimento para quem tenha boas ideias e capacidade de executá-las. 
A teoria econômica liberal rejeita essa associação necessária entre crescimento e industrialização ou mudança estrutural, rejeita políticas que impliquem estímulo à produção de bens cada vez mais sofisticados. Seus adeptos não pensam histórica ou empiricamente, de forma que não importa quais sejam os setores econômicos nos quais o país se especialize, porque supõem que o mercado se encarregará de dizer quais são esses setores, ou, em outras palavras, como uma economia maximiza a utilização de seus recursos produtivos deixando-os governados pelo mercado. Não obstante a evidência empírica seja conclusiva a respeito, apegam-se ao método hipotético-dedutivo, que lhes permite formular e acreditar na teoria do equilíbrio geral. Ora, esse é um método apropriado para as ciências metodológicas, para as quais o critério de verdade é a consistência lógica, como a matemática; não é o método principal adotado para as ciências substantivas (naturais e sociais), que devem adotar o método histórico empírico-dedutivo e ter como critério de verdade a adequação do modelo à realidade. ${ }^{5}$

Existe um velho e ocioso debate entre os economistas que atribuem maior importância ou à acumulação de capital, ou então ao desenvolvimento tecnológico. Essa discussão faz pouco sentido não apenas porque a acumulação de capital vem sempre acompanhada de progresso técnico, como também porque é óbvio que o conhecimento é cada vez mais estratégico para a competitividade das empresas e das nações. Se distinguirmos dois tipos básicos de capital - o capital físico e o capital humano -, verificaremos que a aceleração incessante do progresso técnico vem conduzindo à gradual substituição do primeiro pelo segundo no papel de fator estratégico de produção. Cada vez é mais importante o conhecimento detido pelos indivíduos com competência técnica, administrativa, ou comunicativa - os tecnoburocratas que constituem a classe média profissional. $O$ desenvolvimento econômico decorre tanto da acumulação de capital físico quanto humano, que mantêm entre si certa proporcionalidade técnica: quando um se torna excessivo em relação ao outro, tende a ocorrer o desemprego. Como tendência geral, porém, o segundo tende a prevalecer nos países desenvolvidos, onde existe uma relativa abundância de capital físico, enquanto se verifica uma relativa escassez de capital humano, apesar dos enormes investimentos em educação. Já em países de renda média, como o Brasil, a escassez é dos dois tipos de capital. 


\section{Diminuição das desigualdades e ambiente}

Para muitos economistas, como Celso Furtado e Ignacy Sachs, desenvolvimento econômico implica melhor distribuição de renda, ao passo que crescimento, não. Celso Furtado (2004, p. 484), por exemplo, afirma que o crescimento econômico, tal como o conhecemos, vem se fundando na preservação de privilégios das elites que satisfazem seu afã de modernização; já o desenvolvimento, caracteriza-se por seu projeto social subjacente. Creio que eles estão equivocados ao fazerem essa afirmação. $\mathrm{Na}$ grande maioria, se não em todos os casos de revolução industrial, ocorreu ao mesmo tempo aumento de salários e aumento da desigualdade. Quando afirmamos que para haver desenvolvimento econômico é preciso que haja diminuição das desigualdades, e mais recentemente, que haja adicionalmente proteção do ambiente, estamos abandonando o conceito científico ou empírico de desenvolvimento econômico. Estamos, por exemplo, afirmando que entre 1980 e 2010, quando ocorreu na China o maior crescimento de longo prazo da renda per capita, não houve desenvolvimento econômico. Essa crítica aplica-se também a Amartya Sen $(1989,1999)$, cujo nome está ligado à formulação do Índice de Desenvolvimento Humano. O desenvolvimento econômico implica expansão das capacidades humanas ou aumento da liberdade. Ele está correto quanto ao aumento das capacidades; não há desenvolvimento sem educação. Já seu conceito de liberdade é muito particular, e prefiro não o discutir aqui.

Para Ignacy Sachs (2004, p. 38), existe um desenvolvimento includente e um crescimento excludente ou concentrador: a maneira de definir desenvolvimento includente é por oposição ao padrão de crescimento perverso, conhecido na bibliografia latino-americana como 'excludente' do mercado de consumo e 'concentrador' de renda e de riqueza. Na prática, desde que o desenvolvimento econômico ocorra com aumentos elevados da renda per capita, ele é muitas vezes caracterizado por períodos de aumento das desigualdades combinados com substancial melhoria dos padrões de vida. Normalmente, dois terços da redução da pobreza é causada pelo crescimento da renda por habitante. No caso da China, entre 1980 e 2010, o crescimento da renda per capita foi o maior na história (média de $9 \%$ ao ano) ao mesmo tempo que a desigualdade aumentava fortemente (o índice de Gini subiu de 3,2 para 4,5). Mas nesse período 680 
milhões de pessoas foram tiradas da extrema pobreza; a população pobre da China, que representava $84 \%$ do total em 1980, baixou para $10 \%$ em $2010 .{ }^{6}$ Isso, naturalmente, não justifica a desigualdade, nem implica que o desenvolvimento econômico envolva, necessariamente, aumento da concentração da renda.

O mesmo raciocínio se aplica ao problema ambiental. Historicamente, o desenvolvimento econômico foi inicialmente acompanhado por grande violência contra a natureza. Mas isso não decorreu apenas do fato de ser mais econômico ou barato crescer sem considerar o patrimônio público ambiental; decorreu também do fato de que as sociedades modernas não estavam preocupadas com esse problema. Este só se tornou um objetivo político socialmente partilhado a partir da conferência das Nações Unidas de Estocolmo, de 1972. A partir de então começou uma preocupação real com o desenvolvimento sustentável também do ponto de vista ecológico. Os avanços que se alcançaram nessa matéria são ainda insuficientes; avançou-se certamente menos do que era minimamente necessário em relação ao problema do aquecimento global causado pelo efeito estufa. Mas hoje a proteção da natureza é um objetivo fundamental da humanidade. Por outro lado, a contradição entre o desenvolvimento econômico e o desenvolvimento ambiental é menor do que muitos supõem. O custo de proteger de forma razoável (não de forma perfeita) o ambiente é relativamente baixo. A grande dificuldade em se adotarem as medidas necessárias, entre as quais a principal é um imposto sobre a emissão de gazes poluentes, não é a diminuição da taxa de crescimento mundial que esse imposto provocará, mas o fato de que os países que o adotarem perderão competitividade em relação aos que não cooperarem.

Nem sempre, quando há desenvolvimento econômico, há desenvolvimento humano, mas a contradição entre os dois processos históricos é menor, e a complementaridade, maior do que geralmente se supõe. Pode haver desenvolvimento econômico sem desenvolvimento humano, mas dificilmente poderemos encontrar períodos em que houve desenvolvimento humano sem que houvesse desenvolvimento econômico. No médio prazo, as quatro formas de desenvolvimento humano - a econômica, a política, a social e a ambiental - tendem a ocorrer de forma correlacionada, porque elas estão estruturalmente interligadas e porque elas correspondem a obje-

6 The Economist, 2013, p. 11. 
tivos políticos das sociedades modernas. Entretanto, elas não ocorrem de forma bem-comportada, bem sincronizada, e sim por avanços e recuos, descoordenadamente, como é próprio a todos os processos históricos.

Hoje, a importância do desenvolvimento econômico entre os objetivos políticos das sociedades modernas fica clara pela simples leitura dos jornais. No noticiário interno sobre cada país, vemos que uma grande parte dos esforços de seus governantes está voltada para ele. Na competição eleitoral, na qual os políticos estão permanentemente envolvidos, o critério principal de êxito ou fracasso adotado por eles mesmos e por seus eleitores é o de sua capacidade de promover o desenvolvimento econômico ou a melhoria dos padrões de vida. Nas análises comparativas entre países vemos com frequência a observação que este ou aquele país está ganhando a competição porque sua economia está crescendo mais rapidamente.

Em resumo, para o processo do desenvolvimento econômico concorrem inúmeros fatores que se encadeiam uns aos outros. Como o crescimento decorre da acumulação de capital e do progresso técnico, é essencial saber se os empresários estão sendo estimulados a investir e inovar. Se não existirem estímulos, é sinal de que o problema está na falta de uma estratégia nacional de desenvolvimento. Se o problema enfrentado pelos empresários for a falta de mão de obra e de técnicos, o ponto de estrangulamento estará na educação. Se, pelo contrário, for uma taxa de câmbio incompatível com o investimento em setores com maior valor adicionado per capita, o problema será essencialmente macroeconômico. Os obstáculos ou os pontos de estrangulamento podem, portanto, ocorrer em qualquer ponto da cadeia, mas é sempre importante definir qual é o ponto mais relevante em cada momento. Os obstáculos podem ser internos, como são os casos citados, ou podem ter origem externa. No passado, quando os países ricos argumentavam com a lei das vantagens comparativas para convencer os países em desenvolvimento a não se industrializar, estavam colocando obstáculos ao desenvolvimento desses países por impedir a transferência de sua mão de obra para setores com maior valor adicionado per capita. No presente, quando defendem sua propriedade intelectual excluindo os países em desenvolvimento dos seus benefícios, estão procurando novamente evitar aquela transferência, e, mais concretamente, estão tentando neutralizar a capacidade de competição dos países em desenvolvimento. 


\section{Conclusão}

Neste artigo discuti um velho problema - o do conceito de desenvolvimento econômico - e sua relação com os salários. Voltei ao problema para:

- deixar claro que o conceito relevante de desenvolvimento econômico é o histórico, é a generalização do que efetivamente ocorre, e não o conceito normativo, que reflete apenas nossos valores;

- distinguir desenvolvimento econômico de desenvolvimento humano;

- identificar desenvolvimento econômico com aumento da produtividade, e mais especificamente, como industrialização, mudança estrutural ou sofisticação produtiva (expressões sinônimas);

- distinguir historicamente quatro tipos de desenvolvimento econômico entre os países que já se industrializaram: original central (Inglaterra), atrasado central (Alemanha), periférico autônomo (Coreia do Sul) e periférico nacional-dependente (Brasil);

- reduzir a diferença entre crescimento e desenvolvimento econômico apenas ao caso especial do Estado predador;

- afirmar que o desenvolvimento econômico está intrinsecamente associado ao aumento dos salários e argumentar que existem três causas estritamente econômicas para isso, além do poder de barganha dos trabalhadores:

a) o aumento dos salários é necessário para manter o equilíbrio entre a oferta e a demanda agregada;

b) a taxa de lucro está limitada pela concorrência, de forma que tende a ser constante no longo prazo, enquanto a taxa de salários pode crescer indefinidamente desde que a produtividade do trabalho esteja aumentando;

c) e, finalmente, o aumento dos salários substancialmente acima do nível de subsistência nos países ricos reflete o constante aumento do valor-trabalho da força de trabalho, que é tanto mais alto quanto maior é o investimento em saúde, educação e treinamento em cada pessoa.

- excluir do conceito do desenvolvimento econômico a diminuição das desigualdades e a proteção do ambiente, e, ao mesmo tempo, salientar que

a) esses dois valores fazem parte do conceito de desenvolvimento humano, e 
b) o desenvolvimento econômico é antes uma condição do que um obstáculo para melhor distribuição de renda e principalmente para a luta contra o aquecimento global;

- e, finalmente, assinalar que a sofisticação produtiva, essencial ao desenvolvimento econômico, realiza-se através do aumento da produtividade no mesmo setor e, principalmente nos países em desenvolvimento, através da transferência de mão de obra para os setores mais sofisticados.

Neste artigo não discuti as causas do desenvolvimento econômico, que só ocorre de forma satisfatória quando, no plano microeconômico, o nível de educação é satisfatório, as instituições são favoráveis, a infraestrutura é adequada, e, no plano macroeconômico, a demanda esteja sustentada e os cinco preços macroeconômicos - a taxa de lucro, a taxa de juros, a taxa de câmbio, a taxa de salários e a taxa de inflação - estão equilibrados.

\section{Referências}

AMSDEN, Alice H. (1989). Asia's Next Giant: South Korea and Late Industrialization. New York: Oxford University Press.

ARMSTRONG, Philip; GLYN, Andrew; HARRISON, John (1991). Capitalism Since 1945, 2.ed. Oxford: Basil Blackwell.

BARBOSA LIMA SOBRINHO, Alexandre (1973). Japão: o capital se faz em casa. Rio de Janeiro: Paz e Terra.

BRESSER-PEREIRA, Luiz Carlos (1986). Lucro, acumulação e crise. São Paulo: Editora Brasiliense, 1986.

BRESSER-PEREIRA, Luiz Carlos (2005b). Do ISEB e da CEPAL à teoria da dependência. In: TOLEDO, Caio Navarro de (Org.) (2005). Intelectuais e política no Brasil: a experiência do ISEB. Rio de Janeiro: Editora Revan, p. 201-232.

BRESSER-PEREIRA, Luiz Carlos (2009). Os dois métodos e o núcleo duro da teoria econômica. Revista de Economia Política 29 (2): 163-190.

BRESSER-PEREIRA, Luiz Carlos (2014a). Desenvolvimento, progresso e crescimento econômico. Lua Nova, 93: 33-60.

BRESSER-PEREIRA, Luiz Carlos (2014b). Inequality and the Phases of Capitalism. In: FORUM FOR SOCIAL ECONOMICS 43 (3) Sept., 199-222. Disponível em: <http://dx.doi. org/10.1080/07360932.2014.887589>.

DORE, Ronald P. (1986). Flexible Rigidities: Industrial Policy and Structural Adjustment in the Japanese Economy, 1970-80. Stanford: Stanford University Press.

DUMÉNIL, Gérard; Dominique Lévy (2002). The Profit Rate: Where and How Much Did 
it Fall? Did it Recover? (USA 1948-2000). Review of Radical Political Economy, 34: 437-461.

EVANS, Peter (1992 [1993]). O Estado como problema e como solução. Lua Nova, n. 28/29, 1993. Original em inglês, 1992: 107-157.

FURTADO, Celso (1958). Capital Formation and Economic Development. In: A. N. Agarwala; S. P. Singh (Org). (1958). The Economics of Underdevelopment. New York: Oxford University Press: 309-337.

FURTADO, Celso (1961). Desenvolvimento e subdesenvolvimento. Rio de Janeiro: Editora Fundo de Cultura.

FURTADO, Celso (1967). Teoria e política do desenvolvimento econômico. São Paulo: Companhia Editora Nacional.

FURTADO, Celso (2004). Os desafios da nova geração. Revista de Economia Política, 24(4): 483-486. Discurso na cerimônia de abertura da III Conferência Internacional Celso Furtado. Rio de Janeiro, URFJ, 2004.

GERSCHENKRON, Alexander (1962). Economic Backwardness in Historical Perspective: A Book of Essays. New York: Praeger.

GOODWIN, Richard M. (1967). A Growth cycle. In: C. H. Feinstein, ed. Socialism, Capitalism and Economic Growth. Cambridge: Cambridge University Press: 165-183.

HAUSMANN, Ricardo, HIDALGO, César A. et al. (2014). Atlas of Economic Complexity. Cambridge: Center for International Economic Development of Harvard University and The Observatory of Economic Complexity.

JOHNSON, Chalmers (1982). MITI and the Japanese Miracle. Stanford: Stanford University Press.

KALDOR, Nicholas (1957). A Model of Economic Growth. The Economic Journal, 67 (268): 591-624.

LEÓN-LEDESMA, M. A. (2002.). Accumulation, Innovation and Catching-up: An Extended Cumulative Growth Model. Cambridge Journal of Economics, 26 (2): 201-216.

LEWIS, Arthur W. (1954). Economic Development with Unlimited Supply of Labor. The Manchester School, 22 (2): 139-191.

MEDEIROS, Carlos Aguiar de (2001). Instituições, Estado e mercado no processo de desenvolvimento econômico. Revista de Economia Contemporânea, 5 (1) jan.-jun. 2001: 49-76.

NURKSE, Ragnar (1953). Problems of Capital Formation in Underdeveloped Countries. Oxford: Basil Blackwell.

PREBISCH, Raúl (1949). Commercial Policy and the Underdeveloped Countries. The American Economic Review, v. 44, pp. 241-273.

SACHS, Ignacy (2004). Desenvolvimento includente, sustentável, sustentado. Rio de Janeiro: Garamond/Sebrae.

SCHUMPETER, Joseph A. (1911 [1961]). Theory of Economic Development. Oxford: Oxford University Press, 1961. Publicação original em alemão, 2011.

SEN, Amartya (1989 [1993]). O desenvolvimento como expansão de capacidades. Lua Nova Revista de Cultura Política, n. 28/29, 1993. Original inglês, 1989.

SEN, Amartya (1999). Desenvolvimento como liberdade. São Paulo: Companhia das Letras. 
SIMON, Herbert A. (1957). Models of Man. New York: Wiley. LCCN: 57005933.

WADE, Robert (1990). Governing the Market. Princeton: Princeton University Press.

WEISSKOPF, Thomas (1979). Marxian Crisis Theory and the Rate of Profit in Postwar U.S. Economy. Cambridge Journal of Economics 3(4): 341-378.

\section{Sobre o autor}

Luiz Carlos Bresser-Pereira - bresserpereira@gmail.com Professor emérito da Fundação Getúlio Vargas, São Paulo, SP, Brasil. ORCID: https://orcid.org/0000-0001-8679-0557.

Agradeço ao parecerista anônimo da Nova Economia, que muito me ajudou a melhorar este trabalho.

\section{Sobre o artigo}

Recebido em 13 de janeiro de 2017. Aprovado em 24 de agosto de 2017. 